\title{
Atypical strains of Aeromonas salmonicida contain multiple copies of insertion element ISAsa4 useful as a genetic marker and a target for PCR assay
}

\author{
William B. Nilsson ${ }^{1}$, Nicholas Gudkovs ${ }^{2}$, Mark S. Strom ${ }^{1, *}$ \\ ${ }^{1}$ Northwest Fisheries Science Center, National Marine Fisheries Service, NOAA, 2725 Montlake Boulevard East, \\ Seattle, Washington 98112, USA \\ ${ }^{2}$ Australian Animal Health Laboratory, CSIRO Livestock Industries, Private Bag 24, Geelong, Victoria 3220, Australia
}

\begin{abstract}
The species Aeromonas salmonicida includes a quite complex group of pathogens that cause a variety of diseases in fishes. Best studied strains of this species are those of the subspecies salmonicida also referred to as 'typical' A. salmonicida, which cause furunculosis in salmonids. Less completely understood are bacteria assigned to other subspecies, e.g. achromogenes and masoucida, or those that cannot be assigned to a recognized subspecies. These strains are referred to collectively as 'atypical' A. salmonicida and cause diseases distinct from furunculosis, primarily affecting nonsalmonids. In the course of a study to investigate the suitability of the gene product of $\operatorname{tap} A$ as a subunit vaccine, we discovered several atypical strains of $A$. salmonicida in which the tapA gene was interrupted by an insertion sequence (IS). Subsequent Southern blot analyses indicated that nearly all atypical strains (27 of 29) examined carry many copies of this IS, which we named ISAsa4. Genetic characterization of this IS element revealed it to be a member of the IS5 family, subgroup IS903. Aside from the presence of ISAsa4 in several atypical strains, the nucleotide sequence of tapA was virtually identical to that found in typical strains. This finding suggests that ISAsa4 might be a major source of genetic diversity among atypical strains which, unlike typical strains, are genetically heterogeneous. The presence of ISAsa4 in atypical strains may also help explain the host tropism of atypical strains of this bacterium. Using information on the nucleotide sequences of ISAsa4 from atypical strains of A. salmonicida, primers were designed to selectively amplify genomic DNA from most atypical strains.
\end{abstract}

KEY WORDS: Aeromonas salmonicida - Typical marker · Atypical marker · Insertion sequence · Molecular marker

Resale or republication not permitted without written consent of the publisher

\section{INTRODUCTION}

The bacterial species Aeromonas salmonicida includes a diverse group of fish pathogens that cause disease in both salmonids and non-salmonids (Hiney \& Olivier 1999). The most intensively studied and bestunderstood member of this group is A. salmonicida subsp. salmonicida, also referred to as 'typical' A. salmonicida. This bacterium is a Gram-negative, nonmotile rod that is the causative agent of furunculosis in both salmonids and non-salmonids, and historically has represented a major concern to the salmonid aquaculture industry (Austin \& Austin 1987). A. salmonicida subsp. salmonicida strains isolated from geographically different sites have been shown to have phenotypic similarities and are taxonomically welldefined (Dalsgaard et al. 1994). The genetics of typical strains have also been extensively investigated using molecular approaches that included DNA:DNA hybridization (Belland \& Trust 1988), plasmid profiling (Nielsen et al. 1993), restriction endonuclease fingerprinting (McCormick et al. 1990), randomly amplified polymorphic DNA (RAPD) analysis (Miyata et al. 1995), ribotyping (Nielsen et al. 1994), and pulsed field 
gel electrophoresis (PFGE) (Umelo \& Trust 1998, Livesley et al. 1999, O'hIci et al. 2000). The general conclusion of all of these studies was similar: typical strains of $A$. salmonicida are genetically homogeneous. In fact, the population structure of the subspecies salmonicida has been described as 'clonal' (McCormick et al. 1990, Umelo \& Trust 1998). This characteristic has been attributed to a possibly recent evolutionary origin and/or a specialized ecological niche of A. salmonicida subsp. salmonicida (Boyd et al. 1994).

A less completely characterized group of Aeromonas salmonicida isolates is comprised of strains assigned to the subspecies achromogenes, masoucida and smithia (Hiney \& Olivier 1999), and a proposed new subspecies, pectinolytica (Pavan et al. 2000), as well as many other isolates that, on the basis of phenotypic characteristics, can be identified as A. salmonicida, but cannot be assigned to any recognized subspecies. These isolates, including those assigned to all subspecies other than subspecies salmonicida, are referred to collectively as 'atypical' A. salmonicida. In recent years there has been increasing recognition of the importance of these atypical A. salmonicida subspecies in causing disease conditions in both salmonids and non-salmonids that differ distinctly from those associated with furunculosis. Atypical strains have been identified as the cause of carp erythrodermatitis and ulcer disease in goldfish. The most common clinical manifestation of infections involving atypical strains in other fish species is skin ulcerations that sometimes lead to high mortality. Reports of such epizootics have included farmed salmonid and nonsalmonid species such as Atlantic salmon (Groman et al. 1992), sea trout (Rintamäki \& Valtonen 1991), rainbow trout (Wichardt et al. 1989) and turbot (Pedersen et al. 1994), as well as wild non-salmonids including flounder (Wiklund et al. 1994) and silver perch (Whittington et al. 1995).

The taxonomy of Aeromonas salmonicida remains confusing and controversial. In particular, there is significant difficulty in assigning atypical strains to a specific subspecies (Wiklund \& Dalsgaard 1998). Biochemical profiles appear to be of limited value. In contrast to typical strains, atypical strains have been shown to be genetically heterogeneous by application of RAPD, PFGE, ribotyping (Austin et al. 1998, O'hIci et al. 2000) and amplified fragment length polymorphism (AFLP) (Lund et al. 2002).

At least 3 polymerase chain reaction (PCR) assays for identification of both typical and atypical strains of Aeromonas salmonicida are available. One assay (Hiney et al. 1992), using the 'PAAS' primers, targets a plasmid carried by most but not all strains of $A$. salmonicida. Another assay (Gustafson et al. 1992) utilizes the 'AP' primers that target $\operatorname{vap} A$, a gene encod- ing the virulence-associated surface array protein present in both typical and atypical strains of A. salmonicida. A third assay that appears to be specific for $A$. salmonicida subsp. salmonicida has been described (Miyata et al. 1996); the primers in this assay (MIY1 and MIY2) target cryptic DNA shown by RAPD analyses to be unique to typical $A$. salmonicida. All 3 assays have been extensively evaluated using 308 typical and atypical strains of A. salmonicida (Byers et al. 2002). The PAAS and AP primers were reported to be $100 \%$ specific for A. salmonicida and, taken together, were successful in detecting more than $99 \%$ of the strains in the collection. The MIY1/MIY2 primer pair targeting cryptic DNA present only in typical strains was $100 \%$ sensitive and specific for A. salmonicida subsp. salmonicida strains included in the collection. There is no PCR assay specific for atypical strains currently reported in the literature.

Previous work in this laboratory has focused on the Aeromonas salmonicida tapA gene that encodes the pilin subunit protein of type IV pili. The presence of the type IV pilin was demonstrated to be a determinant for virulence of $A$. salmonicida subsp. salmonicida in rainbow trout (Masada et al. 2002). This finding led us to consider the $\operatorname{tap} A$ gene product as a potential candidate for a subunit vaccine. With this in mind, we acquired a number of strains of this pathogen, both typical $(\mathrm{n}=25)$ and atypical $(\mathrm{n}=29)$, and sequenced the $\operatorname{tap} A$ gene to ascertain the degree of amino acid sequence conservation of the gene product. To our surprise, we found that in all typical strains and many atypical strains, the tapA gene is $100 \%$ conserved at the nucleotide level (data not shown). In the remaining atypical strains the otherwise intact and identical $\operatorname{tap} A$ gene was interrupted by the presence of approximately 1000 nucleotides. Analyses of the inserted nucleotides identified the additional DNA as an insertion sequence (IS), complete with a putative transposase-encoding open reading frame flanked by imperfect inverted repeat sequences. Here we characterize this IS element and demonstrate that it is present in multiple copies only in atypical strains of $A$. salmonicida. We also describe a PCR assay based upon this IS element that specifically identifies atypical strains of A. salmonicida, and differentiates them from $A$. salmonicida subsp. salmonicida.

\section{MATERIALS AND METHODS}

Bacterial strains, growth conditions and DNA template preparation. The bacterial strains used in this study are given in Table 1 . All typical strains were grown on trypticase soy (TS) agar or broth at $22^{\circ} \mathrm{C}$. Some atypical strains, which grew slowly in TS broth, 
Table 1. Aeromonas salmonicida strains used in present study. Strains in which ISAsa4 was inserted within the tapA gene are indicated in bold-face. Superscript after each strain designation indicates donor (see footnotes). na: no data available. AP-1/2: Assay targets vapA gene present in both typical and atypical strains (Gustafson et al. 1992); MIY1/2: assay targets cryptic DNA putatively present in only typical strains (Miyata et al. 1996); ISAsa4F/R: present study (see 'Materials and methods')

\begin{tabular}{|c|c|c|c|c|c|c|}
\hline Strain & Subspecies & Host & Origin & $\mathrm{AP}-1 / 2$ & MIY1/2 & ISAsa4F/R \\
\hline $\mathrm{A} 450^{\mathrm{a}}$ & salmonicida & na & France & + & + & - \\
\hline $49385^{\mathrm{b}}$ & salmonicida & Coho salmon & USA (WA) & + & + & - \\
\hline $364-95^{c}$ & salmonicida & Brown trout & USA (WI) & + & + & - \\
\hline $665-99^{c}$ & salmonicida & Atlantic salmon & Canada (BC) & + & + & - \\
\hline $666-99^{c}$ & salmonicida & Atlantic salmon & Canada (BC) & + & + & - \\
\hline $401-96^{c}$ & salmonicida & Chinook salmon & USA (WA) & + & + & - \\
\hline $362-95^{\mathrm{c}}$ & salmonicida & Rainbow trout & USA (ID) & + & + & - \\
\hline $33658^{\mathrm{b}}$ & salmonicida & Atlantic salmon & Wales & + & + & - \\
\hline $\mathrm{RBT}^{\mathrm{d}}$ & salmonicida & Rainbow trout & USA (ID) & + & + & - \\
\hline Hagerman $^{\mathrm{d}}$ & salmonicida & na & USA (ID) & + & + & - \\
\hline $\mathrm{NB} 8601^{\mathrm{e}}$ & salmonicida & Char & Baltic Sea & + & + & - \\
\hline $\mathrm{NB}_{8801}{ }^{\mathrm{e}}$ & salmonicida & Char & Baltic Sea & + & + & - \\
\hline $3.31^{f}$ & salmonicida & na & na & + & + & - \\
\hline $\mathrm{A} 449^{\mathrm{g}}$ & salmonicida & Brown trout & France & + & + & - \\
\hline $80204^{\mathrm{g}}$ & salmonicida & Atlantic salmon & Canada (NB) & + & + & - \\
\hline $97132^{g}$ & salmonicida & Atlantic salmon & Canada (NB) & + & + & - \\
\hline $80204-1^{g}$ & salmonicida & na & na & + & + & - \\
\hline $\mathrm{SS} 70.1 \mathrm{DS}^{\mathrm{g}}$ & salmonicida & Coho salmon & USA (OR) & + & + & - \\
\hline A450-DFO\#g & salmonicida & na & na & + & + & - \\
\hline NG-109 & salmonicida & Atlantic salmon & Canada (NB) & + & + & - \\
\hline STI.04 & salmonicida & Chinook salmon & USA (WA) & + & + & - \\
\hline $\cos .03^{h}$ & salmonicida & Coho salmon & USA (WA) & + & + & - \\
\hline $19 / 90$ & salmonicida & Turbot & France & + & + & - \\
\hline $\mathrm{FCS}(\mathrm{B})^{\mathrm{h}}$ & salmonicida & Steelhead & USA (WA) & + & + & - \\
\hline $172 / 87^{i}$ & achromogenes & Atlantic salmon & Iceland & + & - & + \\
\hline D1-03/89 ${ }^{i}$ & Atypical & Char & Norway & + & - & + \\
\hline $27013^{i}$ & mascoucida & Masu salmon & Japan & + & - & + \\
\hline AL2939 $^{i}$ & Atypical & Halibut & Norway & + & - & + \\
\hline $\mathrm{K} 110 / 97^{\mathrm{i}}$ & Atypical & Spotted wolffish & Norway & + & - & + \\
\hline th62/94 & achromogenes & Cod & Iceland & + & - & + \\
\hline $98 / 09 / 0632^{i}$ & Atypical & Turbot & Norway & + & - & + \\
\hline $81377^{i}$ & achromogenes & Cod & Canada & + & - & + \\
\hline LH202198j & Atypical & Pacific cod & USA (WA) & + & - & + \\
\hline LH111610 & Atypical & Pacific cod & USA (WA) & + & - & + \\
\hline EKroegSFL3 $^{\mathrm{k}}$ & Atypical & Sablefish & USA (WA) & + & - & + \\
\hline $84: 9062-B 7^{1}$ & Atypical & Goldfish & Australia & + & - & + \\
\hline $85: 9370-A^{1}$ & Atypical & Goldfish & Australia & + & - & + \\
\hline $87: 1147^{1}$ & Atypical & Koi & Australia & + & - & + \\
\hline $03 / 0121^{1}$ & Atypical & Atlantic salmon & Australia & + & - & + \\
\hline $93: 1171-2 A^{1}$ & Atypical & Greenback flounder & Australia & + & - & - \\
\hline WN 92/3136/1 & Atypical & Silver perch & Australia & + & - & + \\
\hline $184 / 76^{1}$ & Atypical & Goldfish & Italy & + & - & + \\
\hline $9 / 72^{1}$ & Atypical & Silver bream & England & + & - & + \\
\hline ATCC $10801^{1}$ & Atypical & Rainbow trout & USA (WV) & + & - & + \\
\hline NCIMB $1110^{1}$ & achromogenes & Brown trout & Scotland & + & - & + \\
\hline NCIMB $2112^{1}$ & Atypical & Minnow & Norway & + & - & + \\
\hline NCIMB $13210^{1}$ & smithia & Rudd & Scotland & + & - & + \\
\hline $89022-1 / 1^{1}$ & Atypical & Flounder & Denmark & + & - & + \\
\hline ME9501 ${ }^{1}$ & Atypical & Amago & Japan & + & - & - \\
\hline N3B ${ }^{1}$ & Atypical & Flounder & Denmark & + & - & + \\
\hline $00 / 0052^{1}$ & Atypical & Atlantic salmon & Australia & + & - & + \\
\hline 02/0027-F1-K ${ }^{1}$ & Atypical & Atlantic salmon & Australia & + & - & + \\
\hline $04 / 2851-1^{1}$ & Atypical & Atlantic salmon & Australia & + & - & + \\
\hline
\end{tabular}


were grown in brain heart infusion broth supplemented with $2 \% \mathrm{NaCl}$ (Lund et al. 2002). Chromosomal DNA was extracted for subsequent analyses according to the procedures described by Strom \& Lory (1986).

Confirmation of strain species assignment. All strains received were identified to at least the species level by the donors. To confirm their designation as Aeromonas salmonicida, all strains were tested using the PCR primers AP-1 and AP-2 (Gustafson et al. 1992) given in Table 2 . These primers target the vapA gene present in both typical and atypical strains of $A$. salmonicida. This and all other PCR assays described in this work were performed using a Techgene thermocycler (Techne) unless otherwise noted. Each $25 \mu \mathrm{l}$ reaction contained $1 \times$ buffer $(50 \mathrm{mM} \mathrm{KCl}, 10 \mathrm{mM}$ Tris$\mathrm{HCl}, \mathrm{pH} 9.0$ and $0.1 \%$ Triton $\left.^{\circledR} \mathrm{X}-100\right), 2.0 \mathrm{mM} \mathrm{MgCl}_{2}$, $400 \mathrm{nM}$ of each primer, $100 \mu \mathrm{M}$ of each dNTP, and $1 \mathrm{U}$ of Taq polymerase (Promega). An initial denaturation step of $2.5 \mathrm{~min}$ at $94^{\circ} \mathrm{C}$ was followed by 30 cycles, each consisting of $30 \mathrm{~s}$ denaturation $\left(94^{\circ} \mathrm{C}\right), 30 \mathrm{~s}$ annealing $\left(57^{\circ} \mathrm{C}\right)$ and $30 \mathrm{~s}$ extension $\left(72^{\circ} \mathrm{C}\right)$ steps followed by a final extension of $9.5 \mathrm{~min}$. The expected product size was 421 base pairs (bp). Confirmation that strains were correctly assigned to the subspecies salmonicida (i.e. designated 'typical') was provided by use of the primers MIY1 and MIY2 (Miyata et al. 1995) (Table 2). This assay was performed under the same conditions used for detection of the $\operatorname{vap} A$ gene, except that the annealing temperature was increased to $65^{\circ} \mathrm{C}$.

PCR amplification of the $\operatorname{tap} A$ gene. The $\operatorname{tap} A$ gene of all strains was amplified using the primers tapasF and tapasR (Table 2). Each $75 \mu$ reaction consisted of $75 \mathrm{ng}$ of template, $7.5 \mu \mathrm{l}$ of $1 \times$ buffer $(20 \mathrm{mM}$ Tris- $\mathrm{HCl}$, $10 \mathrm{mM}\left(\mathrm{NH}_{4}\right)_{2} \mathrm{SO}_{4}, 10 \mathrm{mM} \mathrm{KCl}, 2 \mathrm{mM} \mathrm{Mg}_{2} \mathrm{SO}_{4}$, and $0.1 \%$ Triton X-100), $400 \mathrm{nM}$ of each primer, $100 \mu \mathrm{M}$ of each dNTP, and $1 \mathrm{U}$ of Vent Taq DNA polymerase (New England Biolabs). An initial denaturation step of $94^{\circ} \mathrm{C}$ for 2 min was followed by 30 cycles of denaturation at $94^{\circ} \mathrm{C}$, annealing at $61^{\circ} \mathrm{C}$, and extension at $72^{\circ} \mathrm{C}$, all either $30 \mathrm{~s}$ or $1 \mathrm{~min}$, with a final extension of $9 \mathrm{~min}$ at $72^{\circ} \mathrm{C}$. The $1 \mathrm{~min}$ cycles were applied to those strains in which the tapA gene was interrupted by an IS, resulting in a larger amplicon.

PCR amplification of the insertion sequence ISAsa4. Primers ISAsa4F and ISAsa4R (Table 2) were designed to amplify the insertion sequence ISAsa4 found to be present in most atypical strains (see 'Results'). The $25 \mu$ reactions consisted of $1 \times$ buffer $(50 \mathrm{mM} \mathrm{KCl}$, 10 mM Tris- $\mathrm{HCl}, \mathrm{pH} 9.0$ and $0.1 \%$ Triton $\left.^{\circledR} \mathrm{X}-100\right)$, $2.0 \mathrm{mM} \mathrm{MgCl}_{2}, 400 \mathrm{nM}$ each primer, $100 \mu \mathrm{M}$ each dNTP, and $1 \mathrm{U}$ of Taq DNA polymerase (Promega). The amount of template was varied by addition of $1 \mu \mathrm{l}$ of 10 -fold dilutions of template from Strain 172/87 (stock concentration $65 \mathrm{ng} \mathrm{ml}^{-1}$ ) to establish the appropriate amount of template and the detection limit of the assay for genomic DNA. An initial denaturation step of $94^{\circ} \mathrm{C}$ for 2.5 min was followed by 30 cycles of denaturation at $94^{\circ} \mathrm{C}$, annealing at $67^{\circ} \mathrm{C}$, and extension at $72^{\circ} \mathrm{C}$, all $30 \mathrm{~s}$, with a final extension of $9.5 \mathrm{~min}$ at $72^{\circ} \mathrm{C}$.

Sequence analysis. The PCR products generated with the tapasF/R primer pair were purified using the Ultraclean PCR Cleanup Kit (Mo Bio Laboratories). Purified PCR product (5 to $10 \mathrm{ng}$ ) was then combined with sequencing primer ( $1 \mu \mathrm{M}$ final concentration), $1 \mu \mathrm{l}$ each of $5 \times$ buffer and BigDye Terminator Mix (Applied Biosystems), and water to a total volume of $10 \mu \mathrm{l}$. The reaction mixtures were subjected to cycle sequencing on a PTC-200 DNA Engine (MJ Research) according to the BigDye ${ }^{\circledR}$ Terminator v3.1 Cycle Sequencing Protocol (Applied Biosystems) with an annealing temperature of $55^{\circ} \mathrm{C}$. All of the oligonucleotides listed in Table 2 that are newly reported in this work were used as sequencing primers. Products from cycle sequencing were then prepared for sequence analysis

Table 2. Primers used in present study (ps)

\begin{tabular}{|llcc|}
\hline Primer & Sequence $\left(5^{\prime}{ }^{\prime}{ }^{\prime}\right)$ & Binding location & Source \\
\hline AP-1 & GGCTGATCTCTTCATCCTCACCC & Within vapA & Gustafson et al. (1992) \\
AP-2 & CAGAGTGAAATCTACCAGCGGTGC & Within vapA & Gustafson et al. (1992) \\
MIY1 & AGCCTCCACGCGCTCACAGC & Cryptic DNA & Miyata et al. (1996) \\
MIY2 & AAGAGGCCCCATAGTGTGGG & Cryptic DNA & ps \\
tapasF & GAGTCAGTAGAGGCTCTTCATC & Upstream of tapA & ps \\
tapasR & CTTGGCTCAGGTAACGCTGTG & Within tapB & ps \\
ISAsa4F & CCTGCACCGCCTCATTTCTC & Within ISAsa4 & ps \\
ISAsa4R & GAAAACCCAGTGATCTGAGC & Within ISAsa4 & ps \\
ISAsa4-490F & CCACGATATCGTGAGTCACC & Within ISAsa4 & ps \\
ISAsa4-894F & CAGAAAGTGAGAGAGCCACG & Within ISAsa4 & ps \\
ISAsa4-510R & GGTGACTCACGATATCGTGG & Within ISAsa4 & ps \\
ISAsa4-142R & GTCAAGTGGGAGAAGTGATG & Within ISAsa4 & ps \\
tapA-For & GAAGAAGCAATCAGGCTTTACC & Within tapA & Within tapA \\
tapA-RT & TGCCTGCGCCTACACATGTGC & . & \\
\hline
\end{tabular}


using the CleanSEQ Reaction Clean-Up Kit (Agencourt Bioscience) and sequenced using an ABI 3100 Genetic Analyzer (Applied Biosystems). Sequencing data were analyzed using Sequencher V4.1 (Gene Codes Corporation) and MacVector V 7 (Accelrys).

Southern blot analysis. All strains were digested overnight with BamHI according to the manufacturer's instructions (New England Biolabs). Digests were electrophoretically fractionated on a $0.8 \%$ agarose gel and transferred overnight to positively charged nylon membrane (Roche Diagnostics). A probe for ISAsa4 was constructed by first generating a PCR product from atypical strain 172/87 using primers ISAsa4F and ISAsa4R (see above and Table 2). The resultant $749 \mathrm{bp}$ product was then random-primed labeled with digoxigenin-11-dNTP (Life Technologies). The probed blot was analyzed using the Genius ${ }^{\mathrm{TM}}$ System nonradioactive detection kit (Roche Diagnostics) according to the manufacturer's protocol. The blot was visualized using an Image Station 440CF (Eastman Kodak).

\section{RESULTS}

\section{Confirmation of species and subspecies assignment}

All strains included in this study were confirmed to be Aeromonas salmonicida by PCR assay with primers AP-1 and AP-2 (Gustafson et al. 1992), producing a product of the expected size (Table 1). Primers designed by Miyata et al. (1996) were used to provide evidence that those strains characterized as subsp. salmonicida were assigned correctly. All strains identified as typical gave the expected product of $512 \mathrm{bp}$ (data not shown), while those strains characterized as atypical gave no product (Table 1). In most cases, atypical strains were either non-pigmented or developed pigment more slowly than typical strains.

\section{Sequence analysis of the $\operatorname{tap} A$ gene}

The tapA gene from all 24 typical A. salmonicida subsp. salmonicida isolates was amplified using the primer pair tapasF/tapasR that flanks the entire tap $A$ gene (Table 2). The resultant product in all cases was the correct size (698 bp). Subsequent sequence analyses of the amplicons from all typical strains revealed $100 \%$ identity at the nucleotide level within the 429 nucleotides of the $\operatorname{tap} A$ coding region and all sequences were in complete agreement with the tap $A$ sequence for strain A450 previously deposited in GenBank (Accession No. AF059248). The same primer pair was also used to amplify $\operatorname{tap} A$ from several atypical strains $(n=15)$. Of these strains, 8 produced a product of the expected size and subsequent sequence analyses showed the $\operatorname{tap} A$ sequence for each of these atypical strains to be identical to those of the typical strains. However, PCR amplification of the remaining 7 atypical strains with the same primer pair resulted in a larger product of about $1.7 \mathrm{~kb}$ (data not shown). These 7 strains are shown in bold-face in Table 1. Sequence analyses of the PCR products from these strains revealed that in all 7 strains the $\operatorname{tap} A$ gene is interrupted by a common 1062 bp element. Conceptual translation of this sequence revealed 1 large open reading frame (ORF) spanning most (918 bp) of the element. The amino acid sequence of the putative ORF is predicted to be about $34.6 \mathrm{kD}$ with a theoretical isoelectric point of 10.37. A BLASTX (Altschul et al. 1997) search of GenBank revealed that the ORF is homologous to a number of transposases, with the highest homology (95\% identity and $98 \%$ similarity) to a putative transposase from A. punctata (GenBank Accession No. AAS66621). Of the 7 IS elements examined by DNA sequencing, only minor variation was found in the nucleotide sequence, with only 3 nucleotide substitutions at positions 325, 549 and 1013. Only 1 of the IS sequence variants (from strain EKroegSFL3) results in a change in amino acid sequence relative to the other variants (a change from an aspartic acid, D, to glycine, G, at position 154). All other nucleotide substitutions are either outside the ORF or do not result in any change in the translated product. The nucleotide sequence of a representative strain (EKroegSFL3), in which $\operatorname{tap} A$ is interrupted by the insertion sequence, has been deposited in GenBank (Accession No. AY613940).

This insertion sequence, which we designate ISAsa4, exhibits $18 \mathrm{bp}$ imperfect inverted repeats that begin with the nucleotide sequence GGC, and in most cases, sequence analysis up- and downstream of the insertion site reveals a $9 \mathrm{bp}$ direct repeat. These characteristics, along with the size of the insertion sequence, suggest that ISAsa4 belongs to the IS5 family, subgroup IS903 (Mahillon \& Chandler 1998). Fig. 1 provides a partial alignment of ISAsa4 with other members of this subgroup along with the consensus motif sequence characteristic of this subgroup (Mahillon \& Chandler 1998). Inspection of the amino acid sequence of ISAsa4 in Fig. 1 reveals that it displays the 'DDE motif' characteristic of other members of the IS903 subgroup of the IS5 family (Mahillon \& Chandler 1998).

In those atypical strains with an insertion within the $\operatorname{tap} A$ coding region, the position of the insertion does not appear to be random. ISAsa 4 was inserted between nucleotide positions 9 and 10 of $\operatorname{tap} A$ in strains EKroegSFL3 and 27013, between positions 96 and 97 in th62/94, D1-03/89 and 172/87, and between positions 244 and 245 in AL2939 and 98/09/0632). In one of the 


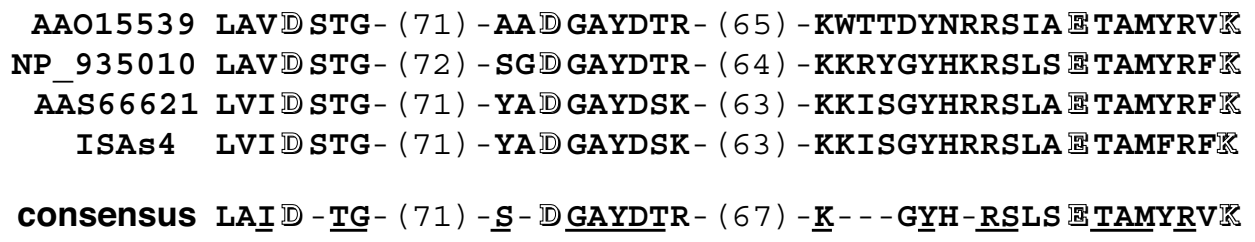

Fig. 1. Alignment of DDE motifs from several members of IS5 family, 903 subgroup (GenBank accession numbers on left) and ISAsa 4 with the consensus motif for this family and subgroup (Mahillon \& Chandler 1998). Outline letters: residues that define conserved motif; boldface, underlined, capital letters: residues conserved within subgroup; boldface capital letters not underlined: predominant residues. Dashes indicate no preference, and numbers in parentheses indicate number of acids between residues in conserved motif

strains (27013) in which the insert was present after position 9 of $\operatorname{tap} A$, no direct repeat was observed. The remaining $\operatorname{tap} A$ gene is absent downstream of ISAsa4, replaced by approximately $500 \mathrm{bp}$ terminating with $21 \mathrm{bp}$ that form a perfect target for the reverse primer tapasR (data not shown). A database search of this $500 \mathrm{bp}$ segment using the BLASTX algorithm produced the best match $(\mathrm{E}=1 \mathrm{e}-8)$ with the RepA (GenBank Accession No. AAB70929), a plasmid replication protein from Pseudomonas alcaligenes (Kwong et al. 2000)

\section{Southern blot analysis of restriction digests of Genomic DNA}

Southern blots of BamHI digests of genomic DNA from all strains were performed and probed with 749 bp of ISAsa4. An example of a Southern blot analysis of selected typical and atypical strains is shown in Fig. 2. The probe hybridizes with a single restriction fragment in typical strains. Consistent with all previous evidence of the rather remarkable genetic homogeneity of Aeromonas salmonicida subsp. salmonicida, this band appears to be of the same size (about $4.5 \mathrm{~kb}$ ) in the typical strains. The complete genome sequence of the typical strain A449 is currently underway at the National Research Council of Canada Institute for Marine Biosciences in Halifax, Nova Scotia. A search of the genomic sequence accumulated to date in this effort found a single contig that included sequence with some homology $(61.0 \%$ identity) to ISAsa4 (Reith \& Boyd pers. comm.), which is the likely source of the single band present in typical strains. With 2 exceptions (see next subsection), all atypical strains examined in this way show many bands (Fig. 2). Since ISAsa4 contains no BamHI recognition sequences, we conclude that many copies $(>30)$ of the insertion sequence are present in these strains. The 5 atypical strains blotted in lanes 6 to 10 are isolates from diverse geographical locations. Comparison of the banding patterns between strains shows some heterogeneity, suggesting that probing with ISAsa4 might be a useful tool for strain differentiation.

\section{Development of PCR assay for specific detection of atypical strains}

Our finding that atypical strains of Aeromonas salmonicida contain many copies of ISAsa4 while typical strains appear to contain a single copy with imperfect homology to ISAsa4 suggested that a PCR assay targeting ISAsa4 could provide a means for direct and specific identification of atypical strains. From the sequence of ISAsa4 and its homolog in A449, primers were designed that were predicted to amplify only ISAsa4 present in atypical strains. Primers ISAsa4F1 and ISAsa4R1 (see Table 2) were predicted to yield a 749 bp product from atypical strains. By amplification of a series of reactions containing 10-fold titration of

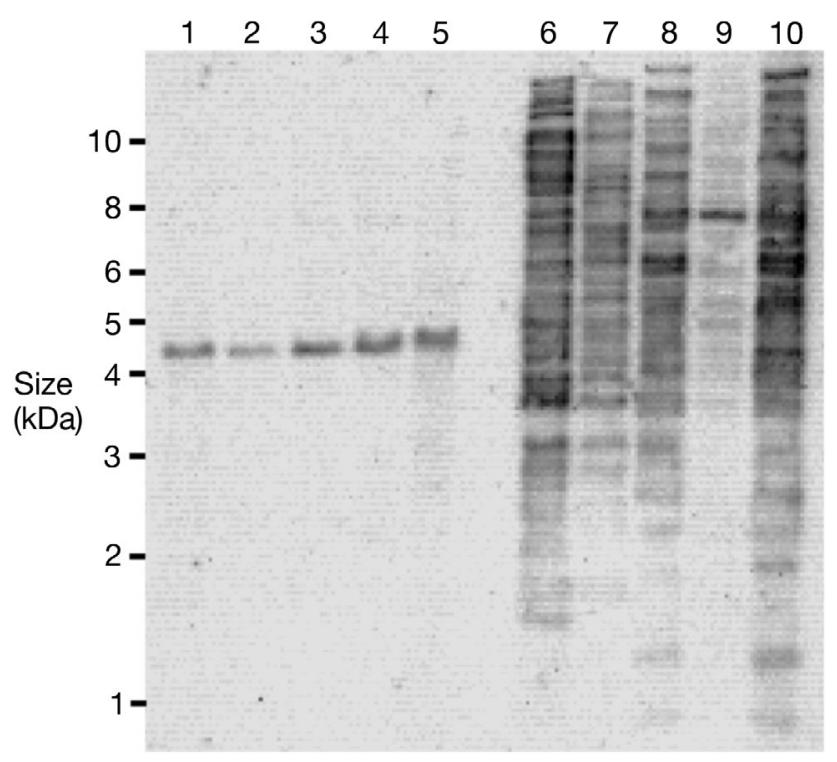

Fig. 2. Aeromonas salmonicida. Southern blot analysis of BamHI digests of $1 \mu \mathrm{g}$ genomic DNA from selected typical and atypical strains. Membrane was hybridized to a digoxigenin-labeled, randomly-primed probe generated by PCR amplification of ISAsa4, using primers ISAsa4F and ISAsa4R (Table 2). Lane 1: A450; Lane 2: A449; Lane 3: 36495; Lane 4: 665-99; Lane 5: NB8801; Lane 6: LH202198; Lane 7: EKroegSFL3; Lane 8: 172/87; Lane 9: 81377; Lane 10: D1-03/89. Molecular weights indicated on left 
the amount of template, we estimate a detection limit of about $250 \mathrm{fg}$ of template (data not shown). Fig. 3B shows results of this PCR assay when tested on 8 typical strains (lanes 3 to 10) and 8 atypical strains (lanes 12 to 19), and demonstrates the specificity of the assay for atypical strains. Fig. 3A shows amplification of the vapA gene (Gustafson et al. 1992) from the same set of strains, thus confirming that all strains are correctly identified as A. salmonicida. When applied to all $54 \mathrm{~A}$. salmonicida strains listed in Table 1, the ISAsa4 PCR assay was found to be negative for all typical strains ( $\mathrm{n}=25$ ), while 27 of 29 atypical strains gave a band of the appropriate size; 2 atypical strains (ME9501 and 93:1171-2A) failed to give a product with the ISAsa4 primers. Both strains were positive when tested with the vapA primers, supporting their identification as $A$. salmonicida, but both were negative for the primer pair MIY1/2 thus suggesting that they are atypical. Genomic DNA from both strains was probed for the presence of ISAsa4 by Southern blot. Unlike the Southern blots of other atypical strains, the blot of 93:11712A had only 2 bands (ca. 13.4 and $5.7 \mathrm{~kb}$ ) while the blot of ME9501 had a single band (ca. $2.3 \mathrm{~kb}$, data not shown). In both cases, the band(s) present differed in size from the single ca. $4.5 \mathrm{~kb}$ band present in similar blots of typical strains (Fig. 2).

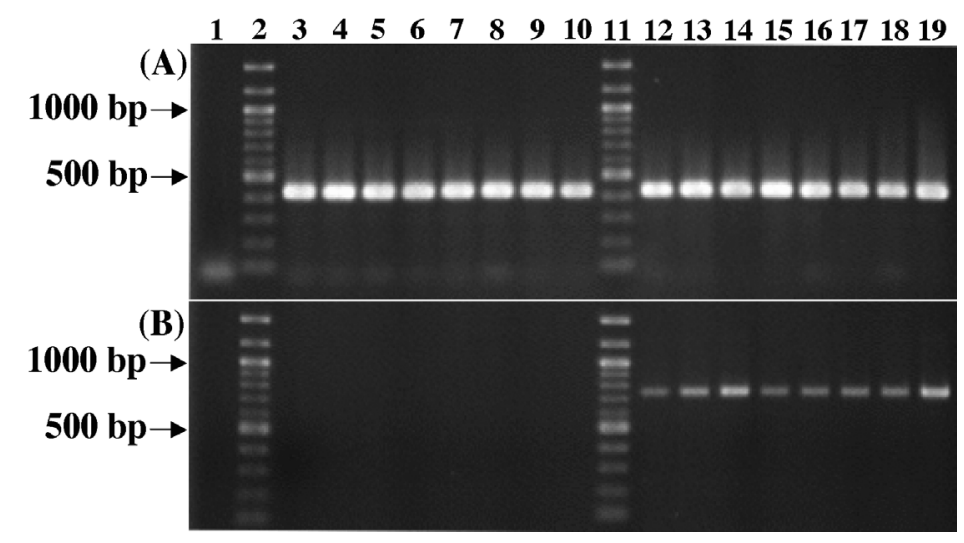

Fig. 3. Aeromonas salmonicida. (A) Amplification of part of gene encoding surface array protein vapA using Primers AP-1 and AP-2 (Table 2). Template was ca. 25 ng genomic DNA from a number of typical (Lanes 3 to 10) and atypical (Lanes 12 to 19) strains. Expected product is $421 \mathrm{bp}$. Lanes 2 and 11 contain a $100 \mathrm{bp}$ ladder, and sizes of major bands are given on left. Lane 1: negative control; Lane 3: A450; Lane 4: 364-95; Lane 5: 362-95; Lane 6: RBT; Lane 7: NB8801; Lane 8: 33658; Lane 9: 401-96; Lane 10: 665-95; Lane 12: 172/87; Lane 13: D1-03/89; Lane 14: 27017; Lane 15: 81377; Lane 16: LH202198; Lane 17: EKroegSFL3; Lane 18: 87:1147; Lane 19: 98/09/0632. (B) Amplification of part of insertion sequence ISAsa4 using Primers ISAsa4F and ISAsa4R (Table 2). Lane assignments as in (A). Expected product is $749 \mathrm{bp}$. For typical strains (Lanes 3 to 10), template was ca. $25 \mathrm{ng}$ genomic DNA, for atypical strains (Lanes 12 to 19) template was ca. 250 pg genomic DNA

\section{DISCUSSION}

A previous study of a large $(n=308)$ collection of both typical and atypical Aeromonas salmonicida strains of worldwide origin was designed to evaluate published PCR assays for detection of this species (Byers et al. 2002). When tested in tandem, the PAAS and AP primers were found to be $100 \%$ specific and nearly $100 \%$ sensitive for detection of both typical and atypical $A$. salmonicida, while the primers designed by Miyata et al. (1996) were found to be $100 \%$ specific for typical strains. Negative results with the primer pair MIY1/MIY2 were considered presumptive evidence that the strain tested was atypical $A$. salmonicida. Based upon evidence presented in this study, our PCR assay utilizing the primer pair ISAsa4F/ISAsa4R designed to target ISAsa4 may be a useful accessory tool for A. salmonicida subsp. characterization using PCR. However, this PCR assay fell short of $100 \%$ sensitivity as it failed to amplify a product of the expected size from 2 of 29 atypical strains tested. Southern blots of both these strains probed with ISAsa4 exhibited far fewer bands than all other atypical strains used in this study, and the sizes of these bands differed from the single band observed in Southern blots of the typical strains in Table 1. It is possible that only partial copies of ISAsa 4 are present in both these strains or that the sequence(s) in the primer binding region(s) are different. In any case, evaluation of this assay on a much larger set of typical and atypical isolates will be necessary to further define its usefulness in A. salmonicida subsp. characterization.

Genetic studies of Aeromonas salmonicida subsp. salmonicida consistently demonstrate remarkable homogeneity when comparing different strains by a variety of fingerprinting methods (Hiney \& Olivier 1999). Our finding that the tapA gene in all typical strains included in this study (obtained from both North America and Europe) were identical at the nucleotide level only serves to underscore the homology among typical strains. We also sequenced a $422 \mathrm{bp}$ portion of the $3^{\prime}$ end of the vapA gene in selected typical strains in Table 1 and found them to be identical at the nucleotide level (data not shown). Recently, an analogous study of the conservation of both nucleotide and predicted amino acid sequences for vap $A$ in typical and atypical strains of $A$. salmonicida has been published elsewhere (Lund \& Mikkelsen 2004). In confirmation of our findings, it was reported that the vap $A$ genes from all 5 typical strains had nearly identical nucleotide sequences. In contrast, sequence analysis of $\operatorname{vap} A$ revealed significant variability in atypical strains at both the nucleotide and amino acid levels. Regions of variability tended to be located in those areas of the vapA gene product predicted to be surface-exposed 
and thus may result in antigenic differences among strains. On the other hand, we find that conservation of the $\operatorname{tap} A$ sequence extends to atypical strains examined in this study, with the nucleotide sequence only differing from that of typical strains by the presence of ISAsa 4 in 7 of the 15 atypical strains in the data set. Given this observation, it is tempting to conclude that the presence of multiple copies (up to 30 or more) of ISAsa4 is, at least in part, the basis for the observed genetic heterogeneity among atypical strains (Austin et al. 1998, O'hIci et al. 2000, Lund et al. 2002). However, considerably more work is necessary to verify this hypothesis.

ISAsa4, like all insertion sequences, is genetically compact and encodes only function(s) necessary for its mobility (Mahillon \& Chandler 1998), which in the case of ISAsa 4 is a single ORF encoding a putative transposase. The length of the ORF (912 bp), the $18 \mathrm{bp}$ inverted repeat and the $9 \mathrm{bp}$ direct repeat generated upon insertion are all characteristic of a member of the IS903 group of the IS5 family. This assignment is strongly supported by the presence of a DDE motif (Mahillon \& Chandler 1998) characteristic of other members of this family (Fig. 1).

While ISAsa 4 is the first reported IS element found in atypical strains of Aeromonas salmonicida, 3 other IS elements have been reported for A. salmonicida subsp. salmonicida. ISAs1 and ISAs2 were found to be involved in the loss of the tetragonal paracrystalline surface protein array (A-layer) that is often observed when strains are grown at $30^{\circ} \mathrm{C}$ (Gustafson et al. 1994). Genetic analyses indicated that this phenomenon was due to insertional deactivation of $\operatorname{vap} A$, the gene encoding the surface protein, by either ISAs1 or ISAs2. Both of the IS elements belong to different families than ISAsa4. A third IS element, ISAs3, is located on plasmid pAsal1 in A. salmonicida subsp. salmonicida (GenBank Accession No. NC_004338). ISAs3 belongs to a different family (IS256) than ISAsa4. It is not known whether atypical strains of A. salmonicida also contain these additional 3 IS elements.

Insertion sequence elements have the capability of inactivating host gene function by specifically inserting into a coding region, as is the case with strains in which ISAsa4 is inserted in $\operatorname{tapA}$. Such mutations are often polar in nature (Galas \& Chandler 1989). Alternatively, insertion can occur in noncoding regions upstream from genes that lack a strong promoter. This can result in significantly increased expression of neighboring genes when an outwardly directed -35 promoter hexamer is oriented in the correct position relative to an existing -10 promoter hexamer (Mahillon \& Chandler 1998). Similarly, insertion can also disrupt existing strong promoters, thus attenuating or silencing gene expression. It seems possible that the progen- itor common to both typical and atypical Aeromonas salmonicida could have acquired ISAsa 4 and, in doing so, activated genes that were previously silent, expanding the host range of the pathogen to include other non-salmonid species. This is, of course entirely speculative. Whatever the genetic impact of ISAsa4 however, the data presented here indicate that it is a useful molecular marker for most atypical strains of $A$. salmonicida.

Acknowledgements. We thank M. E. Peterson of the Northwest Fisheries Science Center Microbiology program for valuable advice and technical assistance and Drs. C. L. Masada and W. W. Dickhoff for helpful reviews of this work. Funding for this research was provided in part by the National Marine Fisheries Service, National Oceanic and Atmospheric Administration, US Department of Commerce. Additional funding was provided through a grant from the National Research Initiative Grants Program (contract number 98-35204-6979) administered by the United States Department of Agriculture.

\section{LITERATURE CITED}

Altschul SF, Madden TL, Schaffer AA, Zhang J, Zhang Z, Miller W, Lipman DJ (1997) Gapped BLAST and PSIBLAST: a new generation of protein database search programs. Nucleic Acids Res 25:3389-3402

Austin B, Austin DA (1987) Bacterial fish pathogens: disease in farmed and wild fish. Ellis Horwood, Chichester

Austin B, Austin DA, Dalsgaard I, Gudmundsdottir BK and 5 others (1998) Characterization of atypical Aeromonas salmonicida by different methods. Syst Appl Microbiol 21: 50-64

Belland RJ, Trust TJ (1988) DNA:DNA reassociation analysis of Aeromonas salmonicida. J Gen Microbiol 134:307-315

Boyd EF, Hiney MP, Peden JF, Smith PR, Caugant DA (1994) Assessment of genetic diversity among Aeromonas salmonicida isolates by multilocus enzyme electrophoresis. J Fish Dis 17:97-98

Byers HK, Gudkovs N, Crane MS (2002) PCR-based assays for the fish pathogen Aeromonas salmonicida. I. Evaluation of three PCR primer sets for detection and identification. Dis Aquat Org 49:129-138

Dalsgaard I, Nielsen B, Larsen JL (1994) Characterization of Aeromonas salmonicida subsp. salmonicida: a comparative study of strains of different geographic origin. J Appl Bacteriol 77:21-30

Galas D, Chandler M (1989) Bacterial insertion sequences. In: Berg DE, Howe MM (eds) Mobile DNA. American Society for Microbiology, Washington, DC, p 102-162

Groman D, Tweedie D, Shaw D (1992) Experiences with atypical furunculosis in Newfoundland: an overview. Bull Aquac Assoc Can 92-1:36-39

Gustafson CE, Thomas CJ, Trust TJ (1992) Detection of Aeromonas salmonicida from fish by using polymerase chain reaction amplification of the virulence surface array protein gene. Appl Environ Microbiol 58:3816-3825

Gustafson CE, Chu S, Trust TJ (1994) Mutagenesis of the paracrystalline surface protein array of Aeromonas salmonicida by endogenous insertion elements. J Mol Biol 237:452-463

Hiney M, Olivier G (1999) Furunculosis (Aeromonas salmoni- 
cida). In: Woo PTK, DW Bruno (eds) Fish diseases and disorders, Vol 3. CABI Publishing, New York, p 341-425

Hiney M, Dawson MT, Heery DM, Smith PR, Gannon F, Powell R (1992) DNA probe for Aeromonas salmonicida. Appl Environ Microbiol 58:1039-1042

Kwong SM, Yeo CC, Suwanto A, Poh CL (2000) Characterization of the endogenous plasmid from Pseudomonas alcaligenes NCIB 9867: DNA sequence and mechanism of transfer. J Bacteriol 182:81-90

Livesley MA, Smith SN, Armstrong RA, Barker GA (1999) Characterization of Aeromonas strains and species by pulsed field gel electrophoresis and principal components analysis. J Fish Dis 22:369-375

Lund V, Mikkelsen H (2004) Genetic diversity among A-proteins of atypical strains of Aeromonas salmonicida. Dis Aquat Org 61:257-262

Lund V, Jenssen LM, Wesmajervi MS (2002) Assessment of genetic variability and relatedness among atypical Aeromonas salmonicida from marine fishes, using AFLPfingerprinting. Dis Aquat Org 50:119-126

Mahillon J, Chandler M (1998) Insertion sequences. Microbiol Mol Biol Rev 62:725-774

Masada CL, LaPatra SE, Morton AW, Strom MS (2002) An Aeromonas salmonicida type IV pilin is required for virulence in rainbow trout Oncorhynchus mykiss. Dis Aquat Org 51:13-25

McCormick WA, Stevenson RM, MacInnes JI (1990) Restriction endonuclease fingerprinting analysis of Canadian isolates of Aeromonas salmonicida. Can J Microbiol 36: 24-32

Miyata M, Aoki T, Inglis V, Yoshida T, Endo M (1995) RAPD analysis of Aeromonas salmonicida and Aeromonas hydrophila. J Appl Bacteriol 79:181-185

Miyata M, Inglis V, Aoki T (1996) Rapid identification of Aeromonas salmonicida subspecies salmonicida by the polymerase chain reaction. Aquaculture 141:13-24

Nielsen B, Olsen JE, Larsen JL (1993) Plasmid profiling as an epidemiological marker within Aeromonas salmonicida. Dis Aquat Org 15:129-135

Nielsen B, Olsen JE, Larsen JL (1994) Ribotyping of Aeromonas

Editorial responsibility: Carey Cunningham,

Aberdeen, UK salmonicida subsp. salmonicida. Dis Aquat Org 18:155-158

O'hIci B, Olivier G, Powell R (2000) Genetic diversity of the fish pathogen Aeromonas salmonicida demonstrated by random amplified polymorphic DNA and pulsed-field gel electrophoresis analyses. Dis Aquat Org 39:109-119

Pavan ME, Abbott SL, Zorzopulos J, Janda JM (2000) Aeromonas salmonicida subsp. pectinolytica subsp. nov., a new pectinase-positive subspecies isolated from a heavily polluted river. Int J Syst Evol Microbiol 50 Pt 3:1119-1124

Pedersen K, Kofod H, Dalsgaard I, Larsen JL (1994) Isolation of oxidase-negative Aeromonas salmonicida from diseased turbot Scophthalmus maximus. Dis Aquat Org 18: 149-154

Rintamäki P, Valtonen ET (1991) Aeromonas salmonicida in Finland - pathological problems associated with atypical and typical strains. J Fish Dis 14:323-331

Strom MS, Lory S (1986) Cloning and expression of the pilin gene of Pseudomonas aeruginosa PAK in Escherichia coli. J Bacteriol 165:367-372

Umelo E, Trust TJ (1998) Physical map of the chromosome of Aeromonas salmonicida and genomic comparisons between Aeromonas strains. Microbiology (Reading) 144 (Pt 8):2141-2149

Whittington RJ, Djordjevic SP, Carson J, Callinan RB (1995) Restriction endonuclease analysis of atypical Aeromonas salmonicida isolates from goldfish Carassius auratus, silver perch Bidyanus bidyanus, and greenback flounder Rhombosolea tapirina in Australia. Dis Aquat Org 22: 185-191

Wichardt UP, Johansson N, Ljungberg O (1989) Occurrence and distribution of Aeromonas salmonicida infections on Swedish fish farms, 1951-1987. J Aquat Anim Health 1: 187-196

Wiklund T, Dalsgaard I (1998) Occurrence and significance of atypical Aeromonas salmonicida in non-salmonid and salmonid fish species: a review. Dis Aquat Org 32:49-69

Wiklund T, Dalsgaard I, Eerola E, Olivier G (1994) Characteristics of 'atypical', cytochrome oxidase-negative Aeromonas salmonicida isolated from ulcerated flounders (Platichthys flesus (L.)). J Appl Bacteriol 76:511-520

Submitted: September 19, 2005; Accepted: February 7, 2006 Proofs received from author(s): June 13, 2006 